GUEST EDITORIAL

\title{
Toward fine-grained phenotyping of suicidal behavior: the role of suicidal subtypes
}

Molecular Psychiatry (2017) 22, 1080-1081; doi:10.1038/mp.2017.123; published online 13 June 2017

Despite advances in the assessment and management of suicidal behavior (SB), suicide remains a leading cause of morbidity and mortality in the United States, and suicide rates have increased dramatically over the past 30 years. ${ }^{1}$ There is ample evidence that suicidal thoughts and behaviors are transdiagnostic phenomena that can arise even in the absence of other diagnosable mental health disorders. ${ }^{2}$ While attempts to elucidate a unified model of SB have identified genetic, neurobiological, and psychological factors that are associated with increased risk, these risk factors, or their combination, have only modest statistical and limited clinical utility. ${ }^{3}$ Thus, predicting who will engage in SB remains challenging. We assert that, rather than being a unified construct, SB likely represents a final common pathway of multiple separate pathological processes. Here, we hypothesize that the pattern of suicidal thinking helps distinguish at least two of these suicidal subtypes.

Three lines of evidence support the notion that SB results from multiple suicidal subtypes. First, there is evidence of associations between particular clinical contexts and features of SB and distinct neurobiological underpinnings. For example, limbic circuits have been implicated in unplanned SB in late life depression, and serotonin receptor $1 \mathrm{~A}$ binding potential in the raphe nuclei has been linked to more lethal SB in depression. ${ }^{4,5}$ Second, contrary to what we would expect with a unified stress-diathesis model, there appears to be an inconsistent relationship between stressful life events and suicidal behavior. ${ }^{6}$ Third, fine-grained assessments have shown that suicidal thinking varies from fluctuating to persistent, and that fluctuating and persistent thoughts of suicide are associated with different risks of SB.,8

In light of this, we posit that there are at least two patterns of suicidal thinking: stress-responsive and non-stress-responsive. ${ }^{9} \mathrm{We}$ further propose that these patterns have their own risk factors and pathophysiology, and that they moderate or mediate the relationship between environmental factors, such as life stressors and access to means, and the timing and lethality of SB. Finally, we think these patterns fit with existing knowledge about SB while potentially explaining some of the observed inconsistencies and limited overall predictive value of established risk factors (Figure 1).

In the stress-responsive pattern of suicidal thoughts, individuals report sudden, potentially fleeting increases in suicidal thoughts following stressful life events. We think that individuals with this pattern of suicidal thinking are at higher risk of less planned SB and that limiting access to means might be particularly important for them. We hypothesize that the stress-responsive pattern is rooted in childhood trauma (CT). CT is a risk factor for suicidal behavior across psychiatric diagnoses, suggesting it plays an independent role in the etiology of suicidal behaviors. ${ }^{10} \mathrm{CT}$ is also associated with impulsive aggression-the tendency to react to perceived threats with an intense, emotional, angry responseamong adults. ${ }^{11}$ Indeed, conceptually, impulsive aggression may serve as a model for the kind of adulthood response to stress following $\mathrm{CT}$ that we propose and has, in fact, also been associated with SB. ${ }^{12}$

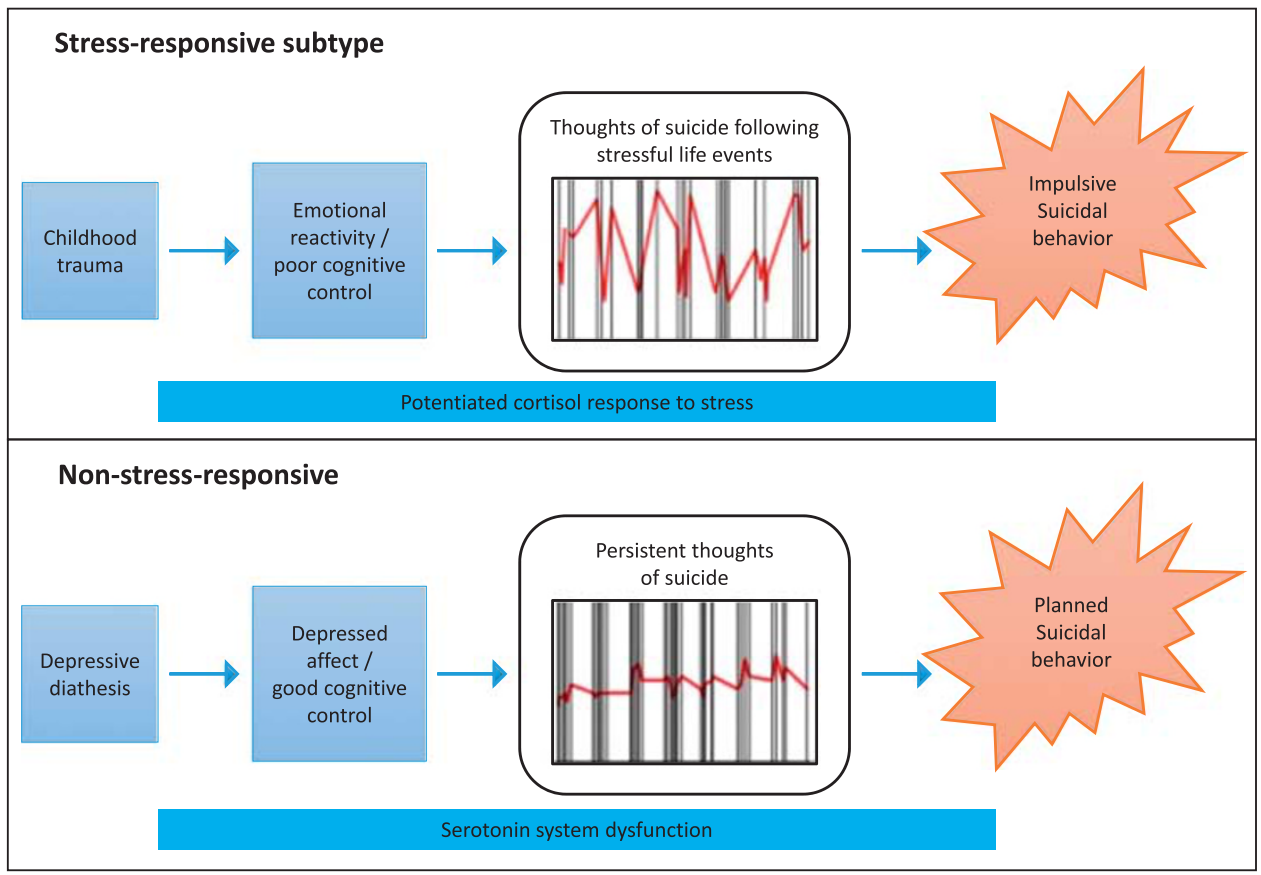

Figure 1. Two proposed suicidal subtypes distinguished by the pattern of suicidal thinking. 
Additionally, human and animal studies have identified persistent serotonin system and hypothalamic-pituitary axis dysregulation following $\mathrm{CT}$, and these same systems have been implicated in SB. ${ }^{13,14}$ Moreover, polymorphisms in serotoninand cortisol-related genes, and also epigenetic modifications to serotonin- and cortisol-related genes, have been specifically linked with $\mathrm{SB}$ following $\mathrm{CT}^{15}$ However, findings regarding hypothalamic-pituitary axis dysfunction, and especially the relationship between cortisol response to stress and SB, are mixed, with some studies showing blunted cortisol response in attempters compared to non-attempters, and others showing heightened response or no difference. ${ }^{16,17}$ The existence of suicidal subtypes might explain these inconsistent findings: our preliminary data suggest that a potentiated cortisol response to stress is integral to the stress-responsive pattern of suicidal thoughts, but not to the non-stress-responsive pattern. ${ }^{18}$

In the non-stress-responsive pattern, individuals are more likely to report persistent thoughts of suicide. We think this pattern is linked to depressive affect and is more likely to result in more carefully planned SB. A variety of studies support these connections. In addition to being one of the criteria for diagnosing major depression, statistical modeling suggests that major depressive episodes play a role in the development of suicidal thinking. ${ }^{19,20}$ Biomarker studies in depression point to a neurobiological basis for more carefully planned SB, with greater intent to die, including an inverse relationship between cerebrospinal fluid serotonin metabolite levels, and SB planning and lethality. ${ }^{21}$ Studies distinguishing less planned and more planned attempts among depressed patients have shown that some risk factors previously linked to SB generally are associated with more planned attempts specifically. These risk factors include more severe and frequent thoughts of suicide, family history of suicide, and greater suicidal intent. ${ }^{22}$ Finally, individuals with histories of more carefully planned attempts demonstrate better cognitive control than those with prior impulsive attempts, implicating executive function and reward circuits in the differential pathogenesis of these suicidal subtypes. ${ }^{23}$

We have described two suicidal subtypes reflecting different patterns of suicidal thinking and stress responsivity, but we suspect there are others. Furthermore, these patterns might overlap or change over time in the same way that psychological and physiological responses to stress alter over the lifespan. ${ }^{24}$ Much work still needs to be done to further operationalize these terms, and to connect this work with existing knowledge. We advocate for integrated research to further delineate suicidal subtypes.

\section{CONFLICT OF INTEREST}

Dr. Bernanke reports no financial relationships with commercial interests. Dr. Stanley receives royalties for the commercial use of the Columbia Suicide Severity Rating Scale. Dr. Oquendo receives royalties for the commercial use of the Columbia Suicide Severity Rating Scale. Her family owns stock in Bristol Myers Squibb.

\section{ACKNOWLEDGMENTS}

This work is funded by the National Institute of Mental Health (5R01MH061017, R01MH109326 and P50 MH090964)

JA Bernanke 1 , BH Stanley ${ }^{2}$ and MA Oquendo ${ }^{3}$ ${ }^{1}$ Department of Psychiatry, New York State Psychiatric Institute, New York, NY, USA; ${ }^{2}$ Department of Psychiatry, Columbia University, New York, NY, USA and

${ }^{3}$ Department of Psychiatry, University of Pennsylvania, Philadelphia, $P A$, USA

E-mail: moquendo@mail.med.upenn.edu

\section{REFERENCES}

1 Curtin SC, Warner M, Hedegaard H. Increase in suicide in the United States, 1999-2014. NCHS Data Brief 2016; 1-8.

2 Oquendo MAA, Baca-García E, Mann JJ, Giner J. Issues for DSM-V: suicidal behavior as a separate diagnosis on a separate axis. Am J Psychiatry 2008; 165: 1383-1384.

3 Franklin JC, Ribeiro JD, Fox KR, Bentley KH, Kleiman EM, Huang X et al. Risk factors for suicidal thoughts and behaviors: A meta-analysis of 50 years of research. Psychol Bull 2017; 143: 187-232.

4 Dombrovski AY, Szanto K, Clark L, Reynolds CF, Siegle GJ. Reward signals, attempted suicide, and impulsivity in late-life depression. JAMA Psychiatry 2013; 70: 1.

5 Sullivan GM, Oquendo MA, Milak M, Miller JM, Burke A, Ogden RT et al. Positron emission tomography quantification of serotonin $(1 \mathrm{~A})$ receptor binding in suicide attempters with major depressive disorder. JAMA Psychiatry 2015; 72: 169-178.

6 Oquendo MA, Perez-Rodriguez MM, Poh E, Sullivan G, Burke AK, Sublette ME et al. Life events: a complex role in the timing of suicidal behavior among depressed patients. Mol Psychiatry 2014; 19: 902-909.

7 Miranda R, Ortin A, Scott M, Shaffer D. Characteristics of suicidal ideation that predict the transition to future suicide attempts in adolescents. J Child Psychol Psychiatry 2014; 55: 1288-1296.

8 Witte TK, Fitzpatrick KK, Warren KL, Schatschneider C, Schmidt NB. Naturalistic evaluation of suicidal ideation: variability and relation to attempt status. Behav Res Ther 2006; 44: 1029-1040.

9 Galfalvy H, Chaudhury SR, Stanley BH. Measuring change in suicidal ideation during an EMA study Montreal, Canada. In: 2015 IASR/AFSP International Summit on Suicide Research, New York, NY, USA, 11-14 October 2015.

10 Bahk YC, Jang SK, Choi KH, Lee SH. The relationship between childhood trauma and suicidal ideation: role of maltreatment and potential mediators. Psychiatry Invest 2017; 14: 37-43.

11 Braquehais MD, Oquendo MA, Baca-García E, Sher L. Is impulsivity a link between childhood abuse and suicide? Compr Psychiatry 2010; 51: 121-129.

12 Conner KR, Swogger MT, Houston RJ. A test of the reactive aggression-suicidal behavior hypothesis: is there a case for proactive aggression? J Abnormal Psychol 2009; 118: 235-240.

13 Gvion Y, Apter A. Aggression, impulsivity, and suicide behavior: a review of the literature. Arch Suicide Res 2011; 15: 93-112.

14 van Heeringen K, Mann JJ. The neurobiology of suicide. Lancet Psychiatry 2014; 1: 63-72.

15 Brodsky BS. Early childhood environment and genetic interactions: the diathesis for suicidal behavior. Current Psychiatry Rep 2016; 18: 86.

16 Melhem NM, Munroe S, Marsland A, Gray K, Brent D, Porta G et al. axis activity prior to suicide attempt and increased inflammation in attempters. Psychoneuroendocrinology 2017; 77: 284-294.

17 Giletta M, Calhoun CD, Hastings PD, Rudolph KD, Nock MK, Prinstein MJ. Multi-level risk factors for suicidal ideation among at-risk adolescent females: the role of hypothalamic-pituitary-adrenal axis responses to stress. J Abnorm Child Psychol 2015; 43: 807-820.

18 Stanley BH. H G: Cortisol Response Predicts Magnitude of Suicide Ideation Increases to Life Events. American College of Neuropsychopharmacology : Hollywood, FL, USA, 2016.

19 American Psychiatric Association Diagnostic and Statistical Manual of Mental Disorders. 5th edn American Psychiatric Publishing: Arlington, VA, USA, 2013.

20 Conner KR, Hesselbrock VM, Meldrum SC, Schuckit MA, Bucholz KK, Gamble SA et al. Transitions to, and correlates of, suicidal ideation, plans, and unplanned and planned suicide attempts among 3,729 men and women with alcohol dependence. J Stud Alcohol Drugs 2007; 68: 654-662.

21 Mann JJ, Malone KM. Cerebrospinal fluid amines and higher-lethality suicide attempts in depressed inpatients. Biol Psychiatry 1997; 41: 162-171.

22 Chaudhury SR, Singh T, Burke A, Stanley B, Mann JJ, Grunebaum M et al. Clinical correlates of planned and unplanned suicide attempts. J Nervous Mental Dis 2016; 204: 806-811.

23 Dombrovski AY, Szanto K, Siegle GJ, Wallace ML, Forman SD, Sahakian B et al. Lethal forethought: delayed reward discounting differentiates high- and lowlethality suicide attempts in old age. Biol Psychiatry 2011; 70: 138-144.

24 Lupien SJ, McEwen BS, Gunnar MR, Heim C. Effects of stress throughout the lifespan on the brain, behaviour and cognition. Nat Rev Neurosci 2009; 10: 434-445.

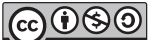

This work is licensed under a Creative Commons AttributionNonCommercial-ShareAlike 4.0 International License. The images or other third party material in this article are included in the article's Creative Commons license, unless indicated otherwise in the credit line; if the material is not included under the Creative Commons license, users will need to obtain permission from the license holder to reproduce the material. To view a copy of this license, visit http:// creativecommons.org/licenses/by-nc-sa/4.0/ 